\title{
Skills training for senior registrars
}

\author{
Results of a survey of recently appointed consultants
}

\author{
Peter Haddad and Francis Creed
}

\begin{abstract}
Nowty appointed consultants in general adult and old age poychiatry were asked to rate how well thelr senior regintrar (SR) training had prepared them for their first year's work as consultants. Troining in 39 specilic skllis was assessed, 14 were rated poorty. In general ferms SR training appeared satisfactory in four areas (clinical skllts, feaching, research, working with groups) but deficient in three areas (general manogement, personal manogement, information technology). SR study days, courses, consultiont superviston and 'hands-on' experience are all potential ways of improving training in these areas. Audit is necesecary to ensure such changes are eflective.
\end{abstract}

The basic aim of higher specialist training is to provide trainees with the skdlls, knowledge and attitudes necessary to work as competent independent practitioners. To date there has been little research into the effectiveness of such training. Such research requires that the aims of higher training are defined in more detail. Plummer (1994) provided a list of core objectives for higher psychiatric training. He believed that all trainees in general and old age psychiatry should achieve these before consultant appointment but stressed that his list was not final and should be changed and improved by debate and research within the profession. Additional skdlls would be needed if practitioners wished to develop special interests or become specialists in certain areas. We conducted a survey in 1995 to provide some basic data regarding the views of recently appointed consultants about the areas in which they had, or had not, been adequately prepared.

\section{The study}

We used Plummer's list of objectives as the basis of a questionnaire. This was sent to the last 26 consultants who had been appointed in general or old age psychiatry after completing senior reglstrar (SR) training on the respective Manchester rotations. The earliest consultant appointment in our cohort was in 1991. The questionnaire was anonymous and consisted of 39 questions, each dealing with a specific skill (e.g. coping with personal stress, supervising junior doctors, use of electroconvulsive therapy). The questions covered seven broad areas of work: 1) clinical skills (17 questions); 2) general management (5 questions); 3) personal management (5 questions); 4) working with groups (4 questions); 5) teaching (3 questions); 6) research (2 questions); 7) information technology (3 questions).

For each question subjects were asked to rate how well their SR training had prepared them for that aspect of their work during their first year as a consultant. Respondents used the following rating scale: $1=$ not at all prepared; $2=$ poorly prepared; $3=$ moderately prepared; $4=$ well prepared; $5=$ very well prepared.

Mean scores were calculated for each question and group means for the seven areas. For analysis questions and areas were divided into those where the mean score was 3.0 or above (i.e. preparation deemed to be moderate or better) and those where the mean was 2.9 or less (i.e. preparations less than moderate).

\section{Findings}

Twenty-four of the 26 consultants returned completed questionnaires giving a response rate of $92 \%$. The mean scores for the 39 skills covered a wide range (Table 1) with the highest being for 'assessment and diagnosis of mental disorders' (mean=4.6) and the lowest for writing a business plan' (mean=1.5). Approximately two-thirds of the skills $(25 / 39)$ recetved mean scores of 3.0 (moderately prepared) or better, though scores of 4.0 (well prepared) or above were uncommon. Approximately one-third of the skills (14/39) received mean scores $<3.0$ and 10 of these were in three areas, general management, personal management and information technology.

\section{Comment}

When considering these results two points need to be remembered. First, the study assessed the views of recently appointed consultants and does not pretend to measure actual skills. Second, consultants may percetve their strengths and 
Table 1. Group means for the seven areas assessed and mean scores for the 39 skills assessed'

(1) Clinical work (group mean=3.6)

1. Assessment/diagnosis of mental disorders 4.6

2. Use of oral psychotroplc drugs $\quad 4.4$

3. Use of depot neuroleptics

4. Use of the Mental Health Act $\quad 4.0$

5. Use of communication skllls

6. Dealing with emergency situations $\quad \cdot \quad 3.8$

7. Working in a community setting

8. Assessing prognosts (Including social and occupational functioning)

9. Use of electroconvulstive therapy (ECD)

10. Awareness of psychodynamic lssues in patient management 3.7

11. Use of counselling skills $\quad 3.6$

12. Attending mental health review tribunals 3.5

13. Assessing patients for referral to speclallist psychotherapy senvees 3.3

14. Witting a court report $\quad 3.0$

15. Use of cognittve-behovioural techniques

16. Dealling with patient/relative complaints

17. Giving evidence in court 1.9

(2) Teaching (including superviston and consultancy sklls) (group mean=3.4)
1. Teaching medical students

2. Supervising junior doctors $\quad 3.6$

3. Consultancy skills (l.e. responding to requests for advice from professionals irespective of 3.2

Cinvolvement with a patient)

(3) Research (group mean=3.3)

1. Possessing a questioning attitude to work 3.5

2. Conducting research

(4) Working with groups (group mean=3.1)

1. Managing a multidisciplinary team

2. Leadership skills $\quad 3.0$

3. Organising/chairing a meeting 3.1

4. Understanding group dynamics 2.9

(5) Personal management (l.e. managing yourself in the following areas) (group mean=2.8)
1. Safety lssues

2. Assertiveness skills $\quad 3.0$

3. Time management $\quad 2.8$

4. Negotiation skills $\quad 2.7$

5. Coping with stress $\quad 2.4$

(6) General management (group mean=2.6)
1. Working with your secretary

$\begin{array}{ll}\text { 1. Working with your secretary } & 3.1 \\ \text { 2. Understanding the administration of the National Health Service (NHS) } & 2.9\end{array}$

3. Conducting audits $\quad 2.8$

4. Understanding the financing of the NHS

5. Witting a business plan 1.5

(7) Information technology (group mean=2.1)

2. Using hospltal information systems $\quad 2.4$

3. Using a spreadsheөt and data base on a personal computer 2.0

1. The seven areas and skills within them are listed in order of decreasing score - they did not appear in this order in the questionnaire. Skills with scores $<3.0$ (moderately prepared) are highlighted in itallics.

weaknesses from a different perspective to SRs. Our respondents may have felt that they had much to learn after their consultant appointment, which may have influenced their retrospective ratings of their SR training. Only four skills recetved mean scores of 4.0 (1.e. well prepared) or above. The paucity of high scores suggests that our respondents had given candid answers and that their training had only moderately prepared them for the many challenges faced on taking up a consultant appointment. It is possible that higher scores would have been obtained if final year SRs had rated their training as they would not be fully aware of these issues.

The variation in the scores is the most helpful part of the data as it can guide our further development of SR training. The four skills in which consultants felt best prepared lassessment/diagnosis of mental disorders, use of oral psychotropic drugs, use of depot neuroleptics and use of the Mental Health Act) are ones where training occurs in both pre- and post-MRCPsych 
posts. Other skills with reasonably high scores (e.g. teaching medical students, supervising junior doctors and managing the multidisciplinary team) only occur in SR posts, but tend to be timetabled activities. For example all Manchester SRs teach medical students and junior doctors on a regular basis and take a research/study day once a week for which supervision is avallable. It is striking that most of the skills with low scores fell into three areas, i.e. general management, personal management and information technology; these areas recetve little attention in current $S R$ training. The bias in training means the results would probably have been similar if consultants in other specialities (e.g. child psychiatrists, forensic psychiatrists) or consultants who trained on other SR rotations had been included.

Deficits in management training were highlighted in a previous survey of SRs and recently appointed consultants (CTC, 1990). Our results suggest that problems still remain despite increased emphasis on the need for management training (McClelland, 1991). Management related activities account for four sessions in most consultant job plans compared to six sessions for clinical work. National Health Service changes mean that management skills are becoming increasingly important. For example dealing effectively with patient and relative complaints is necessary not only in order to provide patients with a high quality service but also in terms of the patient's charter, combating the increase in litigation and the necessity for Trusts to win contracts and be financially successful. Coping effectively with stress is essential for a doctor's quality of life and to reduce stress related illness and associated sick leave within the profession.

Some of the poorly rated skills may be partly explained on the basis of the respondents being appointed up to four years ago and training having improved in the mean time. For example only in recent years have all Manchester SRs been encouraged to complete at least two audit projects during their training. It is only comparatively recently that a special course in cognitivebehavioural treatment has become established in Manchester. Although well attended by SRs, a significant proportion of our cohort were appointed before this course began. The weakness in information technology skills may partly reflect some trainees missing out on the personal computer revolution which continues to gather momentum. The Senior Registrars' Forum, set up in 1993, has organised regional one-day workshops and residential workshops in computer skills and a variety of management topics (Bisson \& Baggaley, 1995). Again many of our cohort were appointed before these courses began. Despite these points the results leave no room for complacency and it was felt that changes were needed in SR training in Manchester.
Many of the skills, for which our training must improve, can be partially taught in formal courses and workshops. Much will be learned, however, by the 'apprentice method' of training with individual consultants. It is hoped that discussion of the list of skdlls in the table, especially those with low scores, will lead to improved training in both formal and informal aspects. This exercise may lead to a list of defined skdlls which can be audited in the future.

\section{Ways forward}

The results of this study have already been discussed at a special meeting of consultants and SRs and suggested ways in which the SR training might be improved were considered. The following plan was adopted:

1) All SRs were sent the results of the survey to raise their awareness of problems that a cohort of SRs ahead of them had experienced. This should allow them to assess their own areas of weakness and allocate personal study, supervision sessions and study leave to address these issues as well as looking for opportunities to gain relevant practical experience.

2) All SR trainers were sent the results with the suggestion that the 14 poorly rated skdlls be used as a menu to be covered in weekly supervision with their SR trainee in addition to current clinical and other subjects.

3) A more structured rolling programme for $S R$ study days is to be developed to ensure that the poorly rated skdlls are covered by group teaching. including workshops, at least once every three years.

4) The results were discussed with the Associate Postgraduate Dean who was devising a new strategy for management training for hospital based junior doctors and dentists within the Region. The new strategy takes account of these findings and refers to them explicitly.

5) All SRs are to be made aware of the range of management courses available within the Reglon and encouraged to attend at least one course during training.

6) 'Hands-on' experience in management skills is to be encouraged. This may take several forms, for example attending and participating at divsional meetings, being an SR representative on medical committees and shadowing a manager.

7) The survey of newly appointed consultants will be repeated in several years time to assess the effect of these changes. Prior to this we aim to survey skills training among current SRs. 
Audit of higher training is essential if standards are to be improved. This is particularly relevant given that the introduction of the Calman Report (DoH, 1993) will require more formalised annual and summattve appraisals of specialist registrars, the replacement grade for SRs. Some key skills and attitudes for effective consultant work are difficult, if not impossible, to assess in a questionnaire format. Consequently such assessments need to be complemented with confidential personal feedback from the SR trainer to the trainee. Finally, it must be remembered that the list of skills we employed may need to be modified and, since training does not finish on consultant appointment, a menu of skills to be acquired (or further developed) during continued professional development needs to be devised.

\section{References}

Bisson, J. I. \& BAGGALEY, M. (1995) Management training at senior registrar level. Psychiatric Bulletin, 19, 648.
Coluggiate Trainees Committee (1990) The CTC Working Party Report on Management Training. Psychiatric Bullettr, 14, 373-377.

DEPARTMENT OF HEALTH (1993) Hospttal Doctors Tratning for the Future. The Report of the Worktng Group on Specialist Medical Trating (Calman Report). London: HMSO.

MCCleLuAND, R. J. (1991) Management and leadership training: the need for an educational strategy. Psychiatric Bullettn, 15, 745-746.

PuMmer, D. (1994) Objectlues for Higher Psychiatric Training. Working Document. London: Royal College of Psychiatrists.

*Peter Haddad, Senior Registrar, Alcohol Treatment Unit, Withington Hospital, Nell Lane, West Didsbury, Manchester, M20 8LR; and Francis Creed, Professor of Community Psychiatry, University of Manchester, Rawnsley Building, Manchester Royal Infirmary, Oxford Road, Manchester, M13 9WL

•Correspondence

\title{
Management for Psychiatrists Second Edition
}

\author{
Edited by Dinesh Bhugra and Alistair Burns
}

Since the last edition rapid changes in the NHS have meant that clinicians have had even less time to manage change and keep up to date with health reforms. For this new edition, all the existing material has been extensively revised. In addition, eight new chapters have been added, including a section on changes and conflicts covering large areas of potential difficulty that clinicians may have to deal with.

As before, the emphasis is on how to get the best for and from services. Practical advice is given on management. Negotiation techniques and time and stress management are also covered.

\section{- $£ 20.00 \bullet 360 p p . \bullet 1995 \bullet$ ISBN 0902241850}

Available from bookshops and from the Publications Department, Royal College of Psychiatrists, 17 Belgrave Square, London SW1X 8PG (Tel. 0171-235 2351 extension 146) 